ha originado, a lo largo de los siglos, innumerables traducciones que han abordado su obra dramática desde perspectivas muy diversas y han hecho hincapié en distintos valores. Como traductores de Shakespeare, nuestro objetivo es subrayar un valor del texto de sumo interés para la traducción: el texto está concebido como una "partitura teatral» (Montalt, 1996) que contiene todas las marcas o apoyos orales y gestuales necesarios para que los actores puedan dar vida a los personajes sobre el escenario. El actor meta requiere un texto meta que le proporcione esas marcas o apoyos en el mismo grado de eficacia en que el texto inglés lo hace para el actor en inglés.

PALABRAS CLAVE: actor, partitura teatral, William Shakespeare, oralidad, traducción teatral.

\title{
Traducir a Shakespeare. La palabra del actor
}

Miguel Teruel Pozas

Universitat de València

Vicent Montalt I Resurrecció

Universitat Jaume I

Pilar Ezpeleta Piorno

Universitat Jaume I
The richness of Shakespeare as a classical playwright has given rise, throughout the centuries, to innumerable translations that have approached his plays from different perspectives and focused on different values. As translators of his plays, we wish to focus on an aspect of the text which is of great relevance as far as translation is concerned: the text is conceived of as a "theatrical score" (Montalt, 1996) containing all the oral and gestural clues the actors need to bring the characters to life on the stage. Actors in the target culture need a text in the target language that provides those same clues as effectively as the English text informs the actors in English.

KEY WORDS: actor, theatrical score, William Shakespeare, orality, drama translation. 
Translate the speech, I pray you, as I pronounced it to you...

Speak the speech, I pray you, as I translated 44 it to you

\section{PRÓLOGO}

No sabemos del todo bien qué es un clásico, o cómo y cuándo se construye, pero quién discute tal categoría a los textos dramáticos de William Shakespeare. En sus obras hay suficiente potencia de conocimiento humano transhistórico como para haber interesado profundamente a las sucesivas generaciones, las cuales - lectores y espectadores, traductores y actores, artistas y académicos, políticos y empresarios - se han empeñado en reconocer y activar tal potencia.

Sugerimos que esta potencia clásica del teatro de Shakespeare, origen del calidoscopio de prácticas culturales e ideológicas en su torno, se hace patente con especial eficacia precisamente por sus específicas cualidades dramáticas. Si todo texto dramático requiere por naturaleza de actualización, las obras shakespearianas son verdaderos almacenes de dramaturgias - personajes, situaciones - apuntadas y posibles, y nunca completamente resueltas ni cerradas.

Si los clásicos lo son también porque se traducen, ¿cómo traducimos a Shakespeare? En este artículo of recemos algunas de las reflexiones que desde hace años nos suscita nuestra experiencia en el proceso de traducción - al castellano y al catalán, a la página y a la escena- de los textos teatrales del dramaturgo inglés ${ }^{\mathrm{I}}$.

La traducción de Shakespeare es una actividad fundamentada en la conciencia estética, dramatúrgica, escénica, fonoestilística, lingüís-

I Véase también: Conejero, Montalt y Tronch (1994); Teruel (1995); Ezpeleta, Montalt y Teruel, (2008). tica, bibliotextual, cultural, ideológica, del texto objeto de trabajo. Tomamos decisiones de traducción en función del valor que atribuimos al texto de partida, de los recursos y posibilidades que nos ofrece nuestro idioma, del contexto en que se utilizará el texto meta, de nuestras ideas sobre lo que es una buena traducción, de la tradición traductora y teatral en la cultura meta, etcétera. De ahí la importancia de saber lo que traducimos y cómo lo traducimos; de comprender de dónde partimos, por dónde transitamos y a dónde llegamos. Las decisiones que toma el traductor responden a las ideas que éste tiene sobre la naturaleza del texto dramático, su forma y su función.

\section{DE LA TRADUCCIÓN DEL CLÁSICO TEATRAL}

Se traduce a Shakesepare porque es un clásico. Shakespeare es un clásico porque se ha traducido y continúa traduciéndose.

No hay duda de que Shakespeare se ha convertido en un clásico por méritos propios, méritos que han sido reconocidos por críticos y estudiosos de su obra, desde Johann Gottfried Herder hasta Johnathan Bate. Sin embargo, a lo largo de los cuatro últimos siglos los traductores han contribuido a que Shakespeare trascienda sus fronteras originales y amplíe el espectro de su público. Cuando Herder escribió su famoso ensayo sobre Shakespeare (I773), lo hizo tras haber leído algunas traducciones alemanas de su época. Sin la lectura de esas traducciones, el crítico alemán no hubiera contribuido al redescubrimiento de Shakespeare y a su establecimiento como clásico universal.

Cada traducción nueva de una obra dramática de Shakespeare está motivada, en último término, por un hecho fundamental: Shakespespeare es un clásico y posee una fuerza y atractivo intrínsecos no agotados hasta la fecha. 
Sus obras continúan siendo espejos de conocimiento e inteligencia humanos que transcienden el espacio y el tiempo en el que fueron creadas. Continúan despertando el interés de nuevos públicos, de nuevos actores, de nuevos directores, de nuevos lectores, de nuevos estudiosos. Permanecen llenas de sentido, a pesar de las innumerables puestas en escena, traducciones, adaptaciones y transformaciones de todo tipo (sinfonías, óperas, etcétera), que se han realizado a lo largo de los siglos (Teruel, r994b). Shakespeare - como Bach, Cervantes, Picasso y otros muchos clásicos- sigue alimentando la necesidad de conocimiento, de experiencia estética y de trascendencia del ser humano. Tanto su contenido como su forma siguen hablándonos de nosotros mismos, siguen emanando belleza y verdad. Shakespeare viaja a través de los siglos, se despliega en infinidad de formas y nos llega con las fuerzas intactas.

Laurence Boswell ${ }^{2}$ afirmaba que el texto shakespeariano podría describirse como un trozo de carbón que alberga en su interior energía en potencia (interpretaciones, puestas en escena, traducciones, etcétera). Puede guardar esa energía durante mucho tiempo sin que se pierda. Sólo cuando se somete a un proceso de combustión (la interpretación por parte del actor, la traducción por parte del traductor, etcétera) libera parte de esa energía potencial, que se transforma en puesta en escena, en traducción a otro idioma, etcétera. Sin embargo, a diferencia del carbón, esta liberación de energía del texto shakespeariano no lo agota. Más bien al contrario, su energía se renueva constantemente y permanece intacta y a disposición de futuras generaciones.

Para captar esta renovación y permanencia

\footnotetext{
2 En comunicación oral. Laurence Boswell es director teatral británico especializado en teatro clásico.
}

de la energía del texto clásico proponemos alterar el sentido de la metáfora. Un trozo de carbón y un diamante son formas distintas de un mismo elemento. El segundo se deriva del primero mediante complejos procesos químicos cuyo desarrollo se produce sólo cuando se dan determinadas condiciones ambientales. $\mathrm{E} 1$ resultado es que las moléculas y átomos del diamante (las palabras, las sílabas, del texto clásico) se encuentran en relación armónica e irradian orden y luz, a diferencia del carbón del que se origina, que presenta una estructura amorfa y se agota en la primera combustión. E1 diamante, cristal precioso, es poliédrico y según el ángulo desde el que se mire, la luz penetrará en él de una manera determinada y permitirá al receptor percibir determinados contornos. No hay manera de allanar el cristal y dejarlo con una sola cara: primero, porque es muy duro (sus enlaces son muy estables); y segundo, porque antes se rompería en mil pedazos.

$\mathrm{Al}$ igual que el diamante, la obra dramática de Shakespeare es poliédrica y compleja. Y en distintos momentos y contextos de la tradición traductora que ha propiciado su despliegue en otras lenguas y culturas, han ido variando los principales focos de atención de los traductores (y también de los estudiosos): el autor y su lugar privilegiado en el canon occidental; el tratamiento de los temas universales del amor, el poder, el sexo, la traición, los celos, etcétera y el sentido último de los mismos; la construcción de los personajes; el valor estilístico y poético del texto; el lector que lee el texto dramático como literatura escrita y los apoyos que necesita para entenderlo; el público teatral que asiste a la representación; las condiciones de representabilidad en el texto; las condiciones culturales del contexto meta; los aspectos ideológicos que determinan la recepción; entre otros.

En este abanico de perspectivas (no nece- 
sariamente excluyentes y, de hecho, a menudo complementarias, al menos en potencia), quizás una de las que menos atención ha recibido es 46 la que se centra primordialmente en el actor, que es el verdadero mediador entre el autor, el personaje y el público. Difícilmente podremos construir el personaje sobre la página en una lengua meta determinada de forma creíble si antes (y simultáneamente), en el proceso de traducción, no lo construimos sobre el escenario de manera imaginada en boca y cuerpo del actor.

\section{DEL TEATRO COMO TRADUCCIÓN}

¿Qué tenemos realmente ante nosotros cuando nos disponemos a traducir, por ejemplo, The Tempest, o cualquier otra obra dramática de William Shakespeare?

Desde la perspectiva de la práctica de la traducción, la respuesta más inmediata a esta pregunta es que The Tempest es un texto escrito que, sobre la página, tiene un aspecto muy similar a cualquier otro texto escrito, a excepción de que, en lugar de párrafos, presenta secuencias en verso o en prosa encabezadas por nombres de personajes. Sin embargo, desde el punto de vista de la comunicación teatral, el texto escrito es un eslabón más en una compleja cadena. El teatro es una ceremonia, un ritual, no solo en lo que ocurre sobre el escenario (Ezpeleta, 2005: 89-94), sino en la comunión entre el escenario y el público. El dramaturgo no escribe para el lector, cuyo contacto material, físico, se limita a las palabras impresas sobre la página; y el resto es imaginación, recreación mental. El dramaturgo procede de un modo muy distinto a como lo hacen el novelista, el poeta, el ensayista, el cronista o el científico. Dicho en otras palabras, el texto es fundamental pero no es el fin, sino que se transforma semióticamente más allá de sí

mismo (ídem, 2007: 48-49, 368). Y está concebido para que así sea.

El dramaturgo traduce a palabras la obra imaginada (Conejero, 199r). Y la traduce pensando no sólo en el público teatral, sino también en el actor que dará cuerpo a los personajes. El director traduce esas palabras a soluciones escénicas concretas que son reflejo de su visión personal, pero también de las preferencias del público, del tipo de encargo que ha recibido, de las condiciones sociales y culturales que le rodean. El actor traduce esas palabras a voz, actitud, gestos y movimientos. E1 público recibe el espectáculo global que constituye el teatro, que se transforma, a su vez, en estados de ánimo, en empatía con los personajes, en emociones estimuladas por la belleza y los contenidos de la obra en cuestión. El lector imagina, a través de las palabras escritas, la puesta en escena y la interacción entre los personajes, sus emociones, sus intenciones, su desarrollo dramático. La tarea del traductor es propiciar esta misma cadena de traducciones en la lengua y contexto de llegada.

Regresemos brevemente a la primera afirmación del párrafo anterior: el dramaturgo traduce a palabras la obra imaginada. El dramaturgo ya es un traductor en dos sentidos. En primer lugar, «traduce» (metafóricamente hablando) la imaginación teatral a lenguaje dramático. En segundo lugar, traduce (adapta, reescribe, parodia $\left.{ }^{3}\right)$ textos anteriores y los transforma en lenguaje dramático (Montalt, 1996). Los ocho volúmenes de Geoffrey Bullough, Narrative and Dramatic Sources of Shakespeare, (1957-1975) dedicados a las fuentes narrativas y dramáticas de la obra de William Shakespeare son buena

3 Entendemos «parodia» como texto que otro texto genera, y usamos el término como «herramienta teórica capaz de dar cuenta del uso que [los autores hacen] de la memoria literaria» (Teruel, 1994a: 8I-84). 
prueba de ello. Si en muchos momentos de su obra Shakesespeare ya es un traductor (en el segundo sentido que apuntamos en el párrafo anterior), si los textos de partida objeto de traducción ya son en cierta medida traducciones, entonces el traductor interlingüístico actual quizás pueda encontrar en muchas secuencias de ellos claves, principios, estrategias, para la traducción, sobre todo en los casos en los que existe bastante proximidad (temática, léxica, etcétera) entre el texto fuente y el texto dramático (Montalt, 1996). Veamos rápidamente cómo reescribe Shakespeare un pasaje procedente de los Ensayos de Montaigne en traducción inglesa de John Florio [ejemplo tomado de Montalt (1996; 1998). Para un comentario más detallado, véase este autor]:

\section{a) Texto fuente}

It is a nation, I would answer Plato, that hath no kind of traffic, no knowledge of letters, no intelligence of numbers, no name of magistrate nor of public superiority, no use of service, of riches or of poverty, no contracts, no successions, no dividences, no occupation but idle, no respect of kindred but common, no apparel but natural, no manuring of lands, no use of wine, corn, metal. The very words that import lying, falsehood, treason, dissimulation, covetousness, envy, detraction, and pardon were never heard of amongst them. How dissonant would he find his imaginary commonwealth from this perfection?

(Instituto Shakespeare, 1993: 45I)

\section{b) Texto meta}

GONZALO I'th' commonwealth I would by contraries

Execute all things. For no kind of traffic Would I admit, no name of magistrate;

Letters should not be known; riches, poverty,
And use of service, none; contract, succession, Bourn, bound of land, tilth, vineyard, none;

No use of metal, corn, or wine, or oil;

No occupation, all men idle, all;

And women too-but innocent and pure;

No sovereignty-

sebastian (To Antonio) Yet he would be king on't.

ANTONio The latter end of his commonwealth forgets the beginning.

GoNZALO All things in common nature should produce

Without sweat or endeavour. Treason, felony, Sword, pike, knife, gun, or need of any engine,

Would I not have; but nature should bring forth

Of its own kind all foison, all abundance,

To feed my innocent people.

sebastian (To Antonio) No marrying'mong his subjects?

Antonio Non, man, all idle: whores and knaves.

gonzalo (To Alonso)

I would with such perfection govern, sir,

T'excell the Golden Age.

SEBASTIAN Save his majesty!

antonio Long live Gonzalo!

(The Tempest, II.i.I53-I75) ${ }^{4}$

Una parte importante del material temático y léxico de esta secuencia de The Tempest procede del texto fuente. Sin embargo, el tratamiento del lenguaje y los efectos del mismo son totalmente distintos. Para los propósitos del presente artículo, destacaremos un aspecto fundamental en este proceso de metamorfosis: Shakespeare construye un texto que contiene las claves orales para su representación/interpretación, un texto que, en manos de un actor, funciona como una partitura en manos de un intérprete musical.

4 Las referencias a las obras de William Shakespeare, salvo que se indique lo contrario, corresponden a Stanley Wells y Gary Taylor, (eds.) William Shakespeare: The Complete Works, Oxford, Clarendon Press, 1988. 


\section{DEL TEXTO COMO PARTITURA PARA EL ACTOR}

48 La comunicación teatral es multidimensional. En ella confluyen fundamentalmente dos niveles: I) la obra y todo lo que en ella ocurre (el universo dramático5); y 2) la puesta en escena delante de un público (el universo escénico). Nos centramos ahora en la relación entre estos dos niveles a través de la figura del actor como mediador y de la necesidad de proporcionar en la traducción las claves que el actor meta necesita para poder construir el personaje sobre el escenario.

En el primer nivel, el dramaturgo construye los personajes y las situaciones sobre la página. El receptor más inmediato de ese texto escrito es el actor, que, después de leerlo y estudiarlo cuidadosamente, habrá de transformar la palabra escrita en acción escénica.

$\mathrm{El}$ actor como lector del texto no solo lee el desarrollo temático y argumental, no solo lee la evolución psicológica de su personaje. Cuando el actor lee el texto escucha cómo hablan los personajes; escucha ritmos, tonos, pausas, velocidades, volúmenes; escucha las actitudes y las emociones de los personajes a través de lo que dicen y también a través de cómo lo dicen; escucha, en definitiva, el gesto oral que encierra cada palabra (Montalt, 2004). En realidad, el actor no superpone su voz al texto escrito, como si éste estuviera desprovisto de sonido, mudo. Más bien al contrario, el actor busca la voz del personaje en el texto y se sirve del texto como herramienta para encontrar su propia voz. Cuando se encuentran ambas, entonces renace el personaje con una nueva piel, que es su destino.

$\mathrm{E} 1$ actor es una pieza fundamental del sis-

5 En relación con la construcción del universo dramático véase Ezpeleta (2007: 49-59). tema mediador sin el cual no es posible pasar al segundo nivel, en el que, respecto al público, el actor ya no es receptor, sino emisor. Se vale de toda la información (e insistimos en «toda») que le proporciona el texto para recrear al personaje.

Este proceso de comunicación tiene una particularidad respecto a otros procesos de comunicación literaria. A diferencia de lo que ocurre con un poema o una novela, el texto dramático está concebido para ser dicho por el actor y para ser escuchado, en último término, por el público, y en primer término por el personaje o los personajes con los que interactúa (y los actores que los materializan). La escucha de un personaje (y de un actor) es tan importante como su intervención activa ya que de ella depende en gran medida la verosimilitud del enlace dialógico (Ezpeleta, 2007: 254-256).

Lo oral y lo auditivo se solapan y constituyen uno de los principales retos para el traductor de Shakespeare: imaginar cómo se dice y cómo suena el texto de partida, en primer lugar; y en segundo lugar, imaginar cómo se dice y cómo suena el texto meta a medida que se le está dando forma (Montalt, 1996). Además, ese mismo texto está concebido para ser corporeizado por el actor en forma de gestos y movimientos, y para ser visto por el público. Esta imaginación oral, auditiva y visual es el fundamento de una traducción basada en las necesidades del actor.

Descendemos ahora a un nivel de concreción mayor para ver cómo el dramaturgo dota el texto de la oralidad necesaria para la creación y representación del personaje. En el siguiente ejemplo — tomado de Montalt (I996). Para un comentario más detallado véase también Montalt (1997) - Shakespeare transforma unos versos de las Metamorfosis de Ovidio en traducción de Arthur Golding en material dramático en boca de Próspero en The Tempest: 


\section{a) Texto fuente}

[...] ye elves of hills, of brooks, of woods alone,

Of standing lakes, and of the night, approach ye every one,

Through help of whom (the crooked banks much wondering at the thing)

I have compellèd streams to run clean backward to their spring.

By charms I make the calm seas rough and make the rough seas plain,

And cover all the sky with clouds and chase them thence again.

(Instituto Shakespeare, 1993: 449-450)

\section{b) Texto meta}

PROSPERO Ye elves of hills, brooks, standing lakes, and groves,

And ye that on the sands with printless foot

Do chase the ebbing Neptune, and do fly him

[...]

Weak masters though ye be, I have bedimmed

The noontide sun, called forth mutinous winds,

And 'twixt the green sea and the azured vault

Set roaring war - to the dread rattling thunder

Have I given fire, and rifted Jove's stout oak

(The Tempest, V.i.33-45)

$\mathrm{Al}$ igual que hemos visto en el primer ejemplo en el que comparábamos la fuente con el texto dramático, el texto resultante utiliza una parte importante del material temático y léxico procedente del intertexto. También observamos que quizás lo que formalmente más se parece al teatro shakespeariano es la poesía. Sin embargo, el verso dramático difiere del verso poético en algunos elementos fundamentales que tienen que ver con las exigencias de oralidad propias del teatro tal y como lo entendía Shakespeare. Una de las principales metamorfosis del texto shakespeariano en este ejemplo es la relacionada con la estructura y extensión del verso. Por una parte, se mantiene el ritmo yámbico $(\cup / \cup$ $/ \cup /$...), si bien con un tratamiento menos rígido y con más variaciones en la distribución de los acentos; es decir, con más licencias métricas, ya que el objetivo es que el personaje hable de manera verosímil, y no que el verso sea formalmente impecable. Por otra parte, se reduce la extensión versal de I4 a ro sílabas, dando como resultado un pentámetro, mucho más cómodo para el actor como unidad de dicción.

En la metamorfosis shakespeariana también cabe destacar tres aspectos más que no se dan en el texto fuente y que en el texto meta constituyen marcas de oralidad de gran valor para el actor: a) los encabalgamientos ( $\mathrm{I}$ have bedimmed / The noontide sun»); b) los hemistiquios («The noontide sun, called forth mutinous winds»); y 3) las inversiones sintácticas («Have I given fire»).

Puesto que el verso dramático está concebido para ser dicho en voz alta, en él confluyen dos fuerzas rítmicas: la derivada del patrón métrico subyacente (pentámetro yámbico) y la derivada de la prosodia propia de la sintaxis de la lengua inglesa. Esta confluencia provoca puntos de divergencia (falta de coincidencia entre acento métrico y acento sintáctico) y puntos de convergencia (coincidencia entre acento métrico y acento sintáctico), que son la base (junto con la cualidad sonora de las palabras individuales) de la riqueza oral de la escritura dramática shakespeariana y convierten el texto escrito en una partitura para el actor (Montalt, I996).

Pero, avancemos un poco más en nuestra argumentación para incorporar un cuarto elemento en la construcción de la partitura: 4) los versos compartidos.

En el universo lingüístico del teatro de Shakespeare, la distinción verso-prosa es siempre activa y significante. Esta distinción es bien informativa, como toda convención. Las convenciones son elipsis narrativas: con ellas se recrean 
mundos de expectativas y, por eficaces, resultan todavía más sugerentes sus transgresiones.

Así sucede en el universo de las obras shakes50 pearianas. Los personajes de alto rango hablan en verso, en verso se dirigen a ellos sus inferiores, $y$ en verso se habla cuando el tema lo requiere por intensidad emocional. En prosa hablan los plebeyos entre sí, y en prosa pueden hablar sus superiores cuando a ellos se dirigen. En prosa oímos jugar con las palabras a bufones filosofantes como Feste, y a fanfarrones verbosos como Paroles. En verso se retratan también los pedantes, como Polonio, y en verso por supuesto se aman los amantes. Pero suenan todas las campanas tonales para advertirnos de que algo importante sucede cuando constatamos que los personajes no hablan como debían, cuando su dignidad versal se resquebraja en prosa. Así es el caso en los procesos de degradación verbal y mental que sufren Lear, y Ofelia, y Lady Macbeth.

Mas el verso no es sólo indicador de relación pragmática entre hablantes. Es sobre todo, y como venimos diciendo, partitura actoral, y su información interna (la prosodia de su ritmo) ayuda inestimable para el recitado $-\mathrm{y}$ la gestualidad, y el movimiento - del actor, que en el verso habrá de descubrir sus propios apoyos: sus pausas, sus aceleraciones, sus subrayados, sus paralelismos, sus ironías.

Por verso aquí nos referimos al prestigiado «blank verse», las tiradas no rimadas de pentámetros yámbicos — cinco pies, predominantemente yámbicos, como en "If music be the food of love, play on» (Twelfth Night, I.i.I) a veces con añadido final de átona o terminación femenina, como en «To be, or not to be; that is the question» (Hamlet, III.i.58) — que constituyen el vehículo principal, casi natural, de las intervenciones de los personajes.

Siendo la lengua inglesa tendente a las unidades fónicas bimembres, y en particular a las yámbicas, el «blank verse» resulta especialmente eufónico al oído nativo. Su naturalidad y flexibilidad hacen del pentámetro yámbico una herramienta sutil y eficaz para la expresión de las gamas de matices con que se construyen los personajes, y un instrumento siempre dispuesto a las diversas interpretaciones de los actores.

Para ilustrar las sutilezas del manejo del «blank verse» en las obras de Shakespeare nada mejor que estar atentos a los momentos en que dos o más personajes comparten pentámetro. Es aquí donde mejor descubrimos hasta qué punto la prosodia sugiere tempo, ritmo y movimiento en la escena.

En el primer ejemplo, tomado de Macbeth, Lady Macbeth interrumpe su invocación cuando aparece Macbeth, y luego continúa su propio verso saludándole con sus nuevos títulos. $\mathrm{Su}$ esposo le completa el último verso con su primera intervención, y el gesto prosódico les invita al abrazo:

LADY MACBETH Come, thick night,

And pall thee in the dunnest smoke of hell,

That my keen knife see not the wound it makes,

Nor Heaven peep through the blanket of the dark

To cry 'Hold, hold!'

\section{Enter Macbeth}

Great Glamis, worthy Cawdor, Greater than both, by the all-hail hereafter, Thy letters have transported me beyond This ignorant present, and I feel now

The future in the instant.

macbeth My dearest love, Duncan comes here tonight.

En los siguientes, la tensión entre los interlocutores se hace palpable, se traduce en el verso y 
de allí a los gestos y movimientos de los personajes. Así, en Macbeth II.ii:

MACBETH I have done the deed. Didst thou not hear a noise?

LADY MACBETH I heard the owl scream and the crickets cry.

Did not you speak?

MACBETH

LADY MACBETH

MACBETH
When?

Now.

As I descended?

(II.ii.I4-I6)

O cuando Lear descubre a Kent encadenado en los cepos (escena 7 en Quarto):

LEAR What's he that hath so much thy place mistook

To set thee here?

KENT It is both he and she:

Your son and daughter.

$\begin{array}{ll}\text { LEAR } & \text { No. } \\ \text { KENT } & \text { Yes. } \\ \text { LEAR } & \text { No, I say. } \\ \text { KENT } & \text { I say yea. } \\ \text { LEAR } & \text { No, no, they would not. } \\ \text { KENT } & \text { Yes, they have. }\end{array}$

(King Lear, Scene vii.r97-200)

\section{$\mathrm{O}$ en Antony and Cleopatra:}

CAESAR Welcome to Rome.

ANTONY Thank you.

CAESAR

Sit, sir.

CAESAR

Nay, then.

They sit

(Anthony and Cleopatra, II.ii.28) ${ }^{6}$

6 Alfred Harbage (ed.) The Complete Pelican Shakespeare. The Tragedies, Harmondsworth, Penguin, I969.
¿Cómo desaprovechar la delicada coreografía verbal diseñada por Shakespeare? El traductor no puede sino tener en cuenta las indicaciones tonales que contiene el verso shakespeariano, y tratar de reproducirlas, así como respetar las unidades fónicas - el número de versos de cada parlamento, o momentos de verso compartido como los señalados. Y respetar también la alternancia verso-prosa, como parte activa y significante del diseño «autoral».

Estos son algunos de los recursos fonoestilísticos que utiliza el dramaturgo para conseguir su propósito. Son los recursos que le ofrece el idioma en el que escribe, el inglés, y también el código estético, estilístico y dramático que da forma a su obra y que es de carácter translingüístico. Obviamente, no todos los idiomas ofrecen los mismos recursos fonoestilísticos, y hay otros recursos que trascienden los límites de una lengua en particular. Así pues, en la tarea del traductor se hace necesaria una reflexión en torno a qué diseños sintácticos y versales se requerirán para conseguir que el texto meta funcione como una partitura para el actor meta, tan bien equipada como la que encontramos en el texto de partida.

En la tradición traductora de Shakespeare al español y al catalán, ha habido de todo. Desde los traductores que optan por eliminar el verso y traducir todo el texto a prosa (Astrana, Valverde), hasta los traductores que optan por un esquema versal altamente regular (MacPherson), pasando por los que prefieren mantener las diferencias entre verso y prosa mediante el uso de un verso con potencialidad oral para la representación (Joan Sellent en catalán o el Instituto Shakespeare en castellano). En cualquier caso, y sin entrar en valoraciones cualitativas ni en motivaciones extratextuales, entendemos que se trata de una decisión traductora de vital importancia y que, por tanto, conviene que se 
fundamente en un conocimiento de los códigos que operan en el texto objeto de traducción.

Lo que Hamlet ordena a los actores en la 52 segunda escena del tercer acto, «Speak the speech, I pray you, as I pronounced it to you...» (Hamlet, III.ii.I-2) ${ }^{7}$, podría extrapolarse como principio interpretativo para cualquier actor ante cualquier personaje shakespeariano. $\mathrm{El} \ll \mathrm{I}$ pronouced it to you» haría, pues, referencia a cómo el texto ya tiene voz propia, a cómo el dramaturgo no solo escribe las palabras sobre la página, sino que las pronuncia en el acto de escribirlas, de manera que el texto se pronuncia a sí mismo. Exactamente del mismo modo que la partitura musical ya suena en la mente de quien la lee, ya contiene las claves de su interpretación.

La misión del actor es encontrar la presencia oral de esas palabras a través de su forma escrita. La misma misión se le podría atribuir al traductor que traduce para el actor.

\section{EPÍLOGO}

Sabemos — desde nuestra experiencia como mediadores en tanto que traductores- que a menudo estamos condenados a la invisibilidad, ya que, a menudo, el fin se superpone a (y se privilegia sobre) los medios en los procesos de comunicación tanto artística como no artística. Lo mismo podría decirse de los actores, que en la mayoría de los casos en su metamorfosis escénica acaban - como leales servidores entregados a la comunión con el público- fundiéndose en los personajes que representan y desapareciendo ante los ojos y oídos del público. Paradójicamente, ahí radica la ilusión de verosimilitud teatral. Ahí radica la magia que buscan

\footnotetext{
7 «Decid los versos, os lo suplico, como yo los he recitado,...» (Instituto Shakespeare, I992: 369).
}

dramaturgo, actor, director y público.

Nuestro principal foco de atención como traductores (aunque no el único) es el actor y su relación con el texto dramático escrito. Si no traducimos para el actor difícilmente podremos traducir para el público. En otras palabras: traducir para el actor es traducir para el público.

Podríamos definir nuestro punto de vista (y también nuestra estrategia traductora) como traducción para el actor; y nuestro ángulo epistemológico como un intento de rescatar al actor de su invisibilidad, al menos en lo tocante a la traducción interlingüística. Esto es así porque muchas decisiones de traducción fundamentales parten de entender el texto dramático como partitura y dependen, por tanto, de criterios relacionados con las necesidades orales y gestuales del actor. Dichos criterios pueden ser totalmente compatibles con otros criterios: bibliotextuales, léxicos, culturales, ideológicos, etcétera.

La relación existente entre texto dramático e interpretación por parte del actor es de vital importancia tanto en la reflexión del traductor como en su quehacer práctico cuando se enfrenta a la obra de Shakespeare. "Translate the speech, I pray you, as I pronounced it to you...» nos remite a cómo el texto nos pide que lo traduzcamos escuchándolo y teniendo en cuenta que tiene que ser dicho. Por su parte, «Speak the speech, I pray you, as I translated it to you...» nos sitúa en la perspectiva del actor meta que puede escuchar la voz del texto meta y encontrar en él las claves orales para su interpretación.

\section{APÉNDICE}

Reproducimos en este Apéndice los fragmentos de la obra de William Shakespeare que han sido objeto de análisis y consideración a lo largo del 
artículo, en la traducción al castellano realizada por miembros del Instituto Shakespeare.

\section{La tempestad, II.i.I47-I70}

gonZalo Todo en mi República se haría al revés.

Ningún tipo de comercio se consentiría, ni habría nombramientos de magistrados.

Nadie sabría nada de letras. Ni habría ricos ni pobres,

$\mathrm{Ni}$ otras servidumbres. ¡ $\mathrm{Ni}$ una! No más contratos,

ni herencias, ni fronteras, lindes, tierras o viñas. ¡Ni una!

nada de metal, grano, vino o aceite.

Nada de trabajo. Sólo hombres en ocio.

Y mujeres también. ¡Pero inocentes y virtuosas!

¡Nada de soberanías!

SEBASTIAN

¡Sin embargo, él sería el rey!

ANTONio convirtiéndose en rey publicano quien era republicano.

gONZALo Todas las cosas de la Naturaleza surgirían

sin sudor y sin esfuerzo. Ni la traición, felonía, espada, pica, cuchillo, ni el arcabuz, o máquina alguna serían necesarias; pues la Naturaleza daría todo tipo de cosecha en abundancia para nutrir a mi inocente pueblo.

SEBASTIAN ¿Ningún matrimonio entre los súbditos?

antonio Pues claro que no: todos ociosos, todos putas y rufianes.

gonZALO Gobernaría con tanta excelencia, señores, que eclipsaría a la Edad de Oro.

SEBASTIAN

¡Salve, majestad!

Antonio ¡Dios salve a Gonzalo!

[Instituto Shakespeare, M. Teruel y J. Tronch (eds.) William Shakespeare: La tempestad, Madrid, Cátedra, I993, pp. 20I-203.]

\section{La tempestad, V.i.33-46}

PRÓSPERo Oh, vosotros, elfos de las colinas, riachuelos, lagos

tranquilos y bosques; $\mathrm{y}$ vosotros que sin dejar huella

en la arena perseguís a Neptuno cuando se retira

[...]

—oh débiles maestrillos— he oscurecido el sol

de mediodía, he despertado los vientos impetuosos

y desatado en guerra estruendosa el verde mar contra la bóveda de azur; yo he prendido el fuego

del terrible trueno estrepitoso, y he astillado el roble de Júpiter $[\ldots]$

$$
\text { (Ib.: 379-38r.) }
$$

\section{Macbeth, I.v.48-57}

LADY MACBETH ¡Ven, noche espesa, ven y ponte el humo lóbrego de los infiernos para que mi ávido cuchillo no vea sus heridas, ni por el manto de tinieblas pueda el cielo asomarse gritando «ibasta, basta!»

(Entra MACBETH.)

¡Gran Cawdor! ¡Noble Glamis! ¡Más grande que los dos, por el profético saludo de lo por venir!

Tus cartas me han llevado más allá de este oscuro presente, y siento ya el futuro de este instante.

MACBETH

Amada mía, Duncan

llega esta noche.

[Instituto Shakespeare (ed.) William Shakespeare: Macbeth, Madrid, Cátedra, I987, p. 99.] 


\section{Macbeth, II.ii.I4-I6}

MACBETH Lo he hecho. ¿No has escuchado nada?

54 [LADY MACBETH] El lamento de un búho y el

llanto de los grillos.

¿No hablaste?

$\begin{array}{lr}\text { MACBETH } & \text { ¿Cuándo? } \\ \text { [LADY MACBETH }] & \text { Ahora. }\end{array}$

MACBETH

¿Mientras descendía?

(Citada: I27-I29.)

\section{El rey Lear, II.iv.II-I4}

LEAR ¿Quién es el que ha malentendido tanto tu lugar, que ahí te ha puesto?

KENT Él y ella a la vez, vuestro hijo y vuestra hija.

LEAR No.

KENT Sí.

LEAR

KENT Y yo digo que sí.

Que no, te digo.

LEAR Que no, no, no podrían.

KENT Sí que pudieron.

[Instituto Shakespeare (ed.) William

Shakespeare: El rey Lear, Madrid, Cátedra, I995, pp. I43-I44.]

\section{Antonio y Cleopatra, II.ii.28}

CAesar Bienvenido a Roma.

ANTONY Gracias.

CAESAR

Sentaos.

ANTONY

Sentaos vos.

CAESAR

Se sientan
[Miguel Teruel (trad. y ed.) William Shakespeare: Antonio y Cleopatra, Biblioteca para el actor, Valencia, Fundación Shakespeare (En prensa)]

RECIBIDO DICEMBRE 2008 ACEPTADO FEBRERO 2009

\section{REFERENCIAS BIBLIOGRÁFICAS}

Bullough, G. (1996) [1957-1975]. Narrative and Dramatic Sources of Shakespeare, Londres: Taylor \& Francis, Routledge.

Conejero, M. Á. (I99I). Rhetoric, Theatre and Translation, Valencia: Fundación Shakespeare.

Conejero, M.Á., V. Montalt i Resurrecció y J. Tronch Pérez, (I994). «Traduir Shakespeare al català: un esforç retòric i teatral», en Actes del Primer Congrés Internacional sobre Traducció, vol. II, Barcelona: Universitat Autònoma de Barcelona, pp. 900-906.

Ezpeleta Piorno, P. (2005). Palabras, palabras, palabras. El decoro en Hamlet, Valencia: Editorial Universidad Politécnica de Valencia.

- (2007). Teatro y traducción. Aproximación interdisciplinaria desde la obra de Shakespeare, Madrid: Cátedra.

Ezpeleta Piorno, P., V. Montalt i Resurrecció y M. Teruel Pozas (2008). «Shakespeare found in translation». Ponencia en el congreso IV Seminar on Shakespeare, Cáceres: Universidad de Extremadura.

Herder, J. G. (2008) [I773]. Shakespeare. Introducción, traducción y edición de G. Moore, Nueva Jersey: Princeton University Press.

Instituto Shakespeare (ed.) (I992). William Shakespeare: Hamlet, Madrid: Cátedra.

Instituto Shakespeare, M. Teruel y J. Tronch (eds.) (1993). William Shakespeare: La tempestad, Madrid: Cátedra.

Montalt i Resurrecció, V. (1996). De la font a la partitura teatral: inscriure l'oralitat en Shakespeare. Tesis doctoral, Valencia: Universitat de València.

Decid, pues. _ (I997). "The isle es full of noises': notes sobre oralitat, visualitat i caos en The Tempest», en A. 
Briz Gómez, M. J. Cuenca Ordinyana y E. Serra (eds.) Quaderns de Filologia de la Universitat de València, Valencia: Publicacions de la Universitat de València.

- (1998). «Traducció i intertextualitat en la gènesi del text original», en L. Messeguer y M. L. Villanueva (eds.) Intertextualitat $i$ recepció, Castellón: Publicacions de la Universitat Jaume I, pp. $245^{-}$ 257.

(2004). «I always write of you': Shakespeare: el gesto en la palabra», en A. Andreu (ed.) El libro de las estatuas, Valencia: Editorial Universidad Politécnica de Valencia, pp. I67-184.
Teruel Pozas, M. (I994a). Tom Stoppard: la escritura como parodia, Valencia: Publicacions de la Universitat de València.

(1994b). A Guide to the Shakespearean Scene, Valencia: The Shakespeare Foundation of Spain.

55

- (I995). «Translating Shakespeare: The Rhetorical Challenge and Performability (A Spanish Experience)», en J. Dodds y L. Avirovic (eds.) La traduzione in scena. Teatro e traduttori a confronto, Roma: Ministero per i beni culturali e ambientali, pp. 2II-222.

Wells, S. y G. Taylor (eds.) (I988). William Shakespeare: The Complete Works, Oxford: Clarendon Press. 